\title{
DE LA VIOLENCIA SURGE UNA CULTURA POLÍTICA DE RESISTENCIA \\ —LAS CPR DEL IXCÁN— QUE DERIVA EN UNA PARTICIPACIÓN ESTRATÉGICA DESDE LAS MUNICIPALIDADES
}

\author{
Práxedes Muñoz Sánchez \\ praxedesm@gmail.com \\ UNIVERSIDAD DE MURCIA, ESPAÑA
}

\begin{abstract}
También nos contaron que habían encontrado gentes nacidas en tierras lejanas y que aunque hablaban en otras lenguas o con otro modo eran como hermanos, pues tenían sentimientos nobles y estaban dispuestos a darnos apoyo y acompañarnos ... Así surgieron los lazos de lucha que hermanan y fortalecen, supimos de los acompañantes y aprendimos que la solidaridad es una fuerza que acerca a las gentes, acorta distancias y permite compartir penas, esfuerzos, logros, sueños y esperanzas...
\end{abstract}

«Sentires», fragmento de relato inédito de Mario Domínguez ${ }^{1}$

\section{RESUMEN}

A partir de una etnografía reflexiva, se prioriza sobre una participación política que ha trascendido hasta hoy por la organización y resistencia durante el conflicto armado interno de Guatemala. Es el caso de personas originarias de las Comunidades de Población en Resistencia, CPR, del Ixcán que han intervenido activamente en los procesos políticos de su municipio, debido en parte a una nueva identidad que emergió y creció con el lema «Resistencia para Avanzar». Apostaron por la organización y por una política activa que, con los Acuerdos de Paz y con proyectos estratégicos de descentralización política, participan en alcaldías municipales apoyándose en las experiencias de organización comunitaria aprendidas durante el conflicto armado interno. Así surgió una nueva cultura política que desde las masacres crea esperanza al pueblo indígena y a la sociedad.

Palabras clave: Cultura política, descentralización, participación política, proyectos estratégicos, resistencia. 


\begin{abstract}
On the basis of reflexive ethnography, the author focuses on the political participation that has taken place to date as a result of the organization and resistance during the internal armed conflict in Guatemala. This is the case of the people from the Ixcán CPRs who have actively intervened in the political processes in their municipality, partly due to their new identity that emerged and expanded as a result of the motto, «Progress through Resistance». They committed themselves to organization and active politics. As a result of the Peace Agreements and through the strategic projects of political decentralization, they participated in municipal town councils, using their experience in community organization from the internal armed conflict. And so a new political culture arose as result of the massacres, creating hope for indigenous people and society.
\end{abstract}

Key words: Political culture, decentralization, political participation, strategic projects, resistance. 


\section{INTRODUCCIÓN}

Este artículo es fruto de parte de las conclusiones y algunos interrogantes alcanzados en la elaboración de mi tesis doctoral sobre una etnografía de las CPR del Ixcán, que abarca desde su origen al asentamiento en su comunidad actual, Primavera del Ixcán. ${ }^{2}$ Cuando llegué a la comunidad, prioricé en las cuestiones organizativa e identitaria generadas durante la resistencia, sin hacer un balance de las consecuencias me interesaban las implicaciones que acarrearon los procesos de resistencia y organización durante el conflicto armado interno para destacar el origen y la existencia de una participación política de índole descentralizadora que se ha estado dando en la municipalidad de Ixcán, Cantabal, en Guatemala. Esta participación la relaciono íntimamente con consideraciones de la propia investigación basándome en las siguientes identidades: a) la resistencia y solidaridad heredada desde su cosmovisión maya; b) el proyecto político de la Unidad Revolucionaria Nacional de Guatemala, URNG, ${ }^{3}$ principalmente con integrantes del Ejército Guerrillero de los Pobres, EGP; c) las personas que se formaron en acciones con la población civil, indígena y campesina, durante el conflicto armado.

De las guerrillas, fue EGP quien creó un vínculo con la población de Ixcán; llegó en 1970 proveniente de México. ${ }^{4}$ Su proyecto político e ideológico se basaba en la «lucha de clases y lucha nacional y étnica», con el fin de derrotar al gobierno apoyándose en la población indígena y campesina que era muy numerosa y la que más sufría las injusticias del gobierno.

Las relaciones con el proyecto político de las CPR fueron encarnadas por la enseñanza y proximidad de personas de la Iglesia católica, fundamentalmente seguidores de la teología de la liberación, así como por integrantes de grupos católicos como Cráter y del Comité de Unidad Campesina, CUC, que desarrollaron una implicación similar y de lucha por la justicia social. Muchos apoyaron sus organizaciones incipientes en las cooperativas de Ixcán tras la colonización reciente en la década de los 60 (IGE 1989, AVANCSO 1992). Durante su resistencia en el conflicto bélico se acercaron organizaciones sociales, de las cuales destaco aquellas que identificaron su lucha social con el proyecto de las CPR del Ixcán, y reclamaban justicia. Asimismo, se fue creando un ideal comunitario gestado a la 
vez en sus estrategias organizativas reforzadas por su producción colectiva, donde muchas personas $y$ organizaciones sociales visualizaron un espejismo socialista o un enamoramiento de su identidad colectiva y de sus estrategias de «Resistencia para Avanzar».

\section{METODOLOGÍA APLICADA}

A causa de plantear un estudio donde existen cuestiones ideológicas y políticas de personas sujetas a ideales, utopías o quimeras de índole socialista, y donde la propia autora se vio involucrada en este aspecto, ha tenido que pasar por las perspectivas emic y etic a razón de visualizar estos determinantes, el yo con el otro que observa Kuper (2001: 271): «El yo real ... se une a la vida espiritual de la comunidad», aplicando una etnografía de tipo reflexiva, priorizando las entrevistas en profundidad junto a la perspectiva emic y etic de los propios sujetos de estudio y de la investigadora.

Los sujetos de estudio en su origen eran las personas integrantes de las CPR del Ixcán, pero debido al involucramiento de múltiples agentes, en su mayoría religiosos e integrantes de EGP, además de otras personas individuales y en colectivo, se llevó a cabo un análisis multireferencial (Velasco y Díaz de Rada 1997) que define a la identidad de la comunidad investigada. De esta forma, era posible conocer los diferentes determinismos, y hallar una visión más complementaria capaz de superar dos de éstos: el general económico (Olson 1971), y el macro sociológico (Touraine 1980, Melucci 1995). Algunos autores proponen diferenciar en este proceso empírico ambas perspectivas en el marco de las teorías generadas en el ámbito iberoamericano, distinguiéndolas de los enfoques europeo y norteamericano, que las combinan en el estudio de los nuevos movimientos sociales.

La identidad comunal es empíricamente abarcable si analizamos dialécticamente «la interrelación existente entre lo que tanto a nivel intra como extra local es observable desde una perspectiva etic [la "comunidad"] con lo que desde una perspectiva emic dota a ésta de sentido para sus miembros y actores» (Dietz 1999: 42). A la que se suma la distinción interrelacionada entre los sujetos de estudio con el investigador, manteniendo estas perspectivas: «entre el investigador-persona, la ciencia-institución, y el grupo estudiado» 
(Dietz 1999: 84), a las que añado el conocimiento antropológico occidental frente a los referentes del sujeto estudiado — comunidades o saberes-, y el proceso personal y político, en este caso de la investigadora durante la realización del trabajo de campo, ya que al adentrarse en un proceso de apoyo comunitario la implicación personal está expresa, junto con otros factores, como el ser mujer, madre, con tendencias políticas socialistas.

La información adquirida desde la observación y la entrevista es en muchos casos suficiente (Velasco y Díaz de Rada 1997) para un método de análisis entre la concepción construida y la discursiva parcial (Dietz 2003). La investigación-acción supera los datos incompletos dándole protagonismo a los grupos sociales estudiados (Montes del Castillo 2000), y la implicación del investigador aporta su propia «originalidad metodológica» y su «auto-instrumentalización»(Velasco y Díaz de Rada 1997: 23), permite al método emic definir la participación del investigador en todo el proceso (Schutter 1987), y se crea así una simbiosis entre la etnografía reflexiva y la investigación-acción. De la última se rescata el despertar de la «memoria colectiva» (López de Ceballos 1989) con los referentes empíricos que en este estudio son los procesos sociales, tanto identitarios como culturales, generados en la comunidad desde su origen, hasta el momento de la realización del trabajo de campo, creando un hábitat entre el pasado reciente y su realidad del ahora.

La recopilación de entrevistas se llevó a cabo en dos momentos, uno en el primer acercamiento a la comunidad, donde fui partícipe del apoyo como acompañante, ${ }^{5}$ realizando tareas de educación de adultos en los cursos de primaria dados por el Instituto Guatemalteco de Educación Radiofónica, IGER. Asimismo, tuve la suerte de ser acogida por varias familias para compartir sus tres comidas al día, lo que me suponía un acercamiento a las mujeres y la vida familiar. ${ }^{6}$ La segunda vez volví a la comunidad con el apoyo de la Universidad de Granada y una beca de la Agencia Española de Cooperación internacional para el Desarrollo, AECID, que me permitió realizar un trabajo de campo más sistematizado para la tesis doctoral. Al regresar a Primavera del Ixcán, la cercanía a las personas de la comunidad resultó mayor, y fui reconociendo mi implicación en las cuestiones ideológicas, las cuales tuvieron que pasar por la visión emic y etic, y así considerar la idealización socialista de la realidad que estaba observando como otro 
instrumento de análisis. Y con el fin de contrastar la etnografía que realicé en 1999-2001, para este estudio revisé la participación política municipal de los últimos años, priorizando sobre las identidades de resistencia y su paso a identidades estratégicas, con bibliografía actualizada, noticias localizadas en Internet y entrevistas a personas cercanas al proceso político que se está viviendo actualmente en Guatemala. ${ }^{7}$

\section{ANTECEDENTES HISTÓRICOS}

Es necesario retomar los procesos históricos de las CPR del Ixcán porque dieron paso a una organización comunitaria que persiste hasta estos momentos con un alto grado de desarrollo rural en relación con otras comunidades de su ubicación. Estos procesos los divido en cuatro momentos: a) colonización y organización en cooperativas — década 1960-1970-; b) intimidación, asesinatos y masacres por parte del ejército gubernamental acusados de posible base guerrillera, principio de los 80 (Falla 1992, IGE 1989, CEH 1999, ODHAG 1998); c) organización de las CPR, y d) su oficialidad saliendo al claro en 1993, declarándose población civil y el reasentamiento en Primavera del Ixcán — cuyo traslado comenzó en 1995.

Ixcán ha sido un territorio peculiar porque casi no estaba poblado y fue fruto de intereses particulares desde el siglo XIX para apropiarse de fincas de café en manos de alemanes, españoles y muchos integrantes del ejército gubernamental, como otras personas de elite, se apropiaron de las mejores tierras para su futura explotación (Piel 1997, Gaudenzi 1992). Está situado en pleno bosque húmedo subtropical provisto de mucha área forestal, donde se produce la mayor cantidad de lluvias de todo el país, desde junio a octubre. A partir de 1966, el gobierno concede tierras para colonizar. Estas se dividieron en tres tipos de colonización, una espontánea, la que se estaba realizando desde México y Alta Verapaz; otras por órdenes religiosas, en este caso los sacerdotes Mariknoll y los misioneros del Sagrado Corazón; y una tercera colonización en manos de proyectos del Estado (Sosa 2001, AVANCSO 1992). Los Mariknoll crearon la cooperativa de Ixcán Grande, misma que destacó por un desarrollo muy óptimo en cuanto a los cultivos y el 
desarrollo comunitario. ${ }^{8}$ Teniendo en cuenta el medio tan hostil y la falta de vías de acceso, se proveyeron de avionetas para trasladar su producción, a enfermos, y para otros usos.

Los colonos que llegaron eran fundamentalmente de Huhuetenango y de El Quiché, en primer lugar de los pueblos kanjobal, chuj y mam, y posteriormente quiché, cakchiquel, kekchí, rabinal acchí y pocomchí, además de ladinos ${ }^{9}$ que también arribaron hacia estas tierras. La colonización fue provocada por el propio gobierno, ya que quería «abrir brecha» en un área deshabitada, hostil pero que a la vez iba a ser una futura vía, la Franja Transversal del Norte del país, FTN, por donde extraer principalmente petróleo y níquel. De ahí que la presencia militar del ejército gubernamental se hacía latente a la vez que llegaban colonos, y más cuando EGP, Ejército Guerrillero de los Pobres, hace su primera acción violenta pública. Para el control de sus acciones, el ejército se infiltraba en las cooperativas, estratégicamente crearon la figura del «comisionado militar» para vigilar más de cerca cualquier movimiento de la guerrilla, fundamentalmente a finales de los años 70 .

Rosada (1999) describe los objetivos del ejército para destruir las posibles células organizadas por la guerrilla en la población; la violencia del ejército aumentó cuando efectuó la campaña Victoria 82, denominada Tierra arrasada, con el gobierno de Ríos Montt (1982-1983), devastando y masacrando a las comunidades que identificaron como posibles fuentes de guerrilleros, además de base logística: «Ciertas áreas se convierten en objetivo militar para matanzas masivas: es decir, el ejército debe tratar a los civiles a quienes va a "rescatar" como si fueran combatientes, matando y quemando a todos los seres vivos dentro del "área asegurada"» (Schirmer 2001: 88). La población campesina tuvo que huir, primero a sus parcelas, que estaban un poco alejadas del núcleo poblacional, y posteriormente se organizaron en grupos de familias, huyendo hacia México o quedándose escondidos. Ambas opciones fueron apoyadas por la guerrilla, tanto en la autodefensa como en el desplazamiento. En este momento surge la población desplazada que se convierte en refugiados, así como los grupos de población en resistencia, que dieron lugar a la organización clandestina de las CPR del Ixcán, consideradas éstas como población organizada en resistencia o población «retenida» por la guerrilla: 
Yo siento que la interponían [a la población] para tener fines que se estaba atacando a la población civil como población retenida, en 1982 yo lo demostraba a los periodistas que la mayoría de población sabía sus fines y propósitos militares ... Hay también violación a los derechos humanos porque existía la perfidia, cuando tú utilizas un derecho para fines militares utilizas un recurso que no debe ser atacado como a la población civil, ellos al mundo lo decían así, quizás no eran combatientes pero eran utilizados para proteger a sus combatientes (E-militar O. N. 01).

En la siguiente ilustración se observa los desplazamientos de la población tras las ofensivas militares:

Ilustración 1. Periodo de pacificación militar 1982-1984

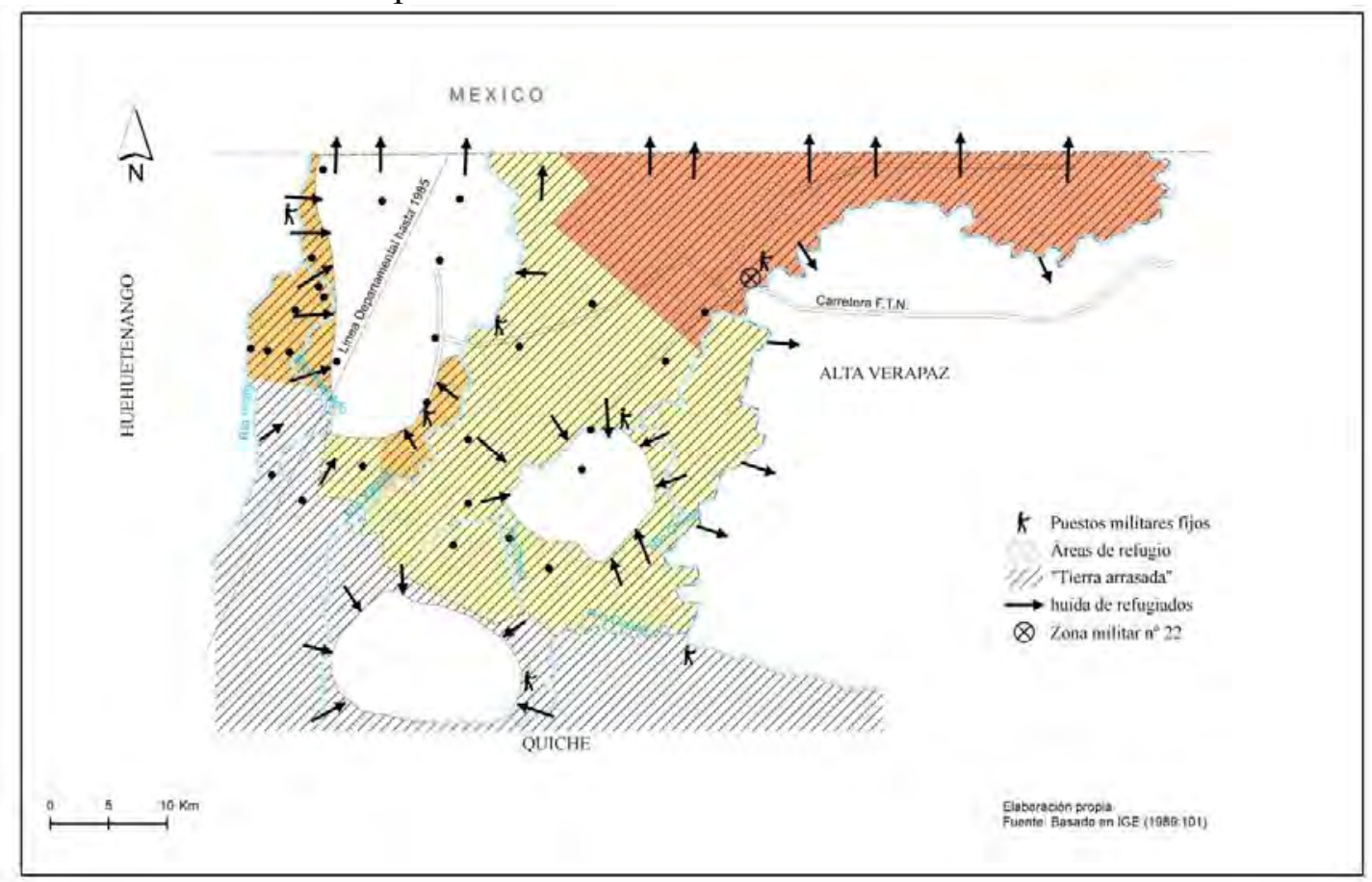

Fuente: IGE (1989: 101).

Desde las masacres hasta que comienzan a tratarse los Acuerdos de Paz, la población de CPR se mantuvo escondida pero con una activa vida, no solo de estar atenta a las amenazas y cercanías del ejército gubernamental, sino a la vez creando una organización comunitaria para poder sobrevivir a la guerra de una forma más digna, conformando organizaciones 
políticas basadas en un sistema asambleario y representativo, formando a promotores de salud y educación, creando un sistema de producción colectiva y sirviéndose de EGP en el apoyo de su autodefensa y formación de la vigilancia durante el propio conflicto bélico, con apoyos mutuos en logística, compra y correo, fundamentalmente. En 1992 se declaran oficialmente como población civil no armada que sufre una continua violencia, con bombardeos de parte del ejército gubernamental. ${ }^{10}$ Posteriormente a los Acuerdos de Paz, se desplazan a su comunidad actual, Primavera del Ixcán, donde conviven: población refugiada, desmovilizada de EGP y originaria de las CPR. Actualmente mantienen su organización comunitaria y luchan por mejorar sus vidas ante las dificultades de los distintos gobiernos. No les es fácil el desarrollo de los proyectos productivos para hacer frente al pago de la tierra de su comunidad actual, pero siguen con el sistema cooperativista y con su activismo político, afrontando limitaciones del sistema económico actual más individualista.

\section{INTENCIÓN DE EGP EN IXCÁN}

Cuando EGP se hace visible en Ixcán, ya está listo para enfrentarse a un nuevo momento, gestado desde las experiencias anteriores a sus orígenes en las Fuerzas Armadas Revolucionarias, FAR. ${ }^{11}$ El nacimiento de esta nueva vanguardia se debió al conjunto de dinámicas que confluyeron en la necesidad de crear una organización nueva políticomilitar. ${ }^{12} \mathrm{Su}$ estrategia principal fue «la participación de la población civil, la consideración de la cuestión étnica-nacional y la búsqueda a lo largo del conflicto del equilibrio entre el factor militar y [el] factor político» (CEH 1999, cap. 2, párr. 1545, p. 270).

Creo que hay que recordar que la filosofía del EGP es la cuestión campesina, la cuestión indígena, desde sus inicios la plantea, plantea el problema étnico en la ciudad, en la cuestión étnica nacional no se puede dejar de hablar del campesinado, ni se puede dejar de hablar del pueblo maya, entonces la gente se vio identificada con esa idea, y por otro lado como que la propia represión, la propia brutalidad del ejército, desbordó, hizo que la gente no encontrara otro camino (E- CUC/CPR E. T. 01). 
A EGP le movían muchas razones, la principal era una lucha contra los ricos, contra la desigualdad, de esta forma se acercaron a la población más pobre, que a la vez era indígena. ${ }^{13}$ Le Bot (1995: 116) recoge cuatro objetivos alcanzados por EGP de parte del comandante Benedicto, responsable del Frente Urbano: ser una organización políticomilitar que superara diferencias entre partido y guerrilla de los 60; incorporar del campesinado indígena aspectos topográficos y geoestratégicos; localización en regiones de poca presencia gubernamental, y apoyarse en el recurso de una base de apoyo local. A partir de 1975, en El Quiché, los primeros indígenas que respondieron a la llamada de la guerrilla solían ser los más organizados: «catequistas, miembros de cooperativas o de ligas campesinas, comerciantes...» (Le Bot 1995: 117). También existió, entre otros, la participación de miembros del CUC, junto a ex jesuitas que deciden abandonar sus labores religiosas e identifican sus luchas con la opción de la guerra de guerrillas.

El EGP, con su estrategia de guerra popular revolucionaria, se fue consolidando durante tres etapas; destaco la segunda y tercera por su relación con las CPR: $2^{\mathrm{a}}$ etapa, 1979-1983, «la guerra de guerrillas»; y la $3^{\text {a }}$ etapa 1983-1996: «recuperación de masas, terreno y poder». Se mantienen los dos principales frentes: Ho Chi Minh y Ernesto Guevara (CEH 1999). A la vez, en 1982 se produce la unificación de las guerrillas en URNG. Existía una crisis interna de la dirección, la cual es descriptiva en la población de estudio como causa de la falta de armas, a lo que hay que añadir una derrota estratégica militar y la búsqueda de un reconocimiento en el ámbito internacional (Payeras 1998: 49); que coincide con el levantamiento y éxito en El Salvador y Nicaragua.

La estrategia de guerra de guerrillas perseguía, con un claro objetivo, tomar el Estado, pero a la vez ir desde la base ganando espacios en la lucha, que muchos militantes de EGP observaban en las CPR: «Para nosotros ver cómo vivía la población era la visión en pequeño de por qué estábamos luchando para cambiar este mundo lleno de injusticias» (E-EGP H. Barrios 00). Esta estrategia es considerada por muchos autores de utilitarismo de las bases, ${ }^{14}$ revirtiendo en las tácticas de EGP: «concentrando su estrategia alrededor de cuestiones como el refugio, el retorno y las CPR, por medio de las cuales buscaban apoyo y reconocimiento a nivel internacional» (CEH 1999, cap. 2, párr. 1598, p. 287). 
... se trata de comunidades en resistencia; porque en realidad en una población heroica que hace una resistencia al enemigo dentro de las profundidades de nuestro territorio ... Sobrevive de dos maneras. Una se da en zonas muy agrestes adonde el ejército no llega por temor a ser interceptado. Allí la población tiene instalaciones que forman la aldea y ponen sus casas y la producción a disposición de las fuerzas guerrilleras. La otra modalidad es la población que se mueve y se instala en la selva con instalaciones provisionales. Son difíciles de detectar para el enemigo y tienen un carácter mucho más móvil que las otras, porque allí tienen preparado todo para salir en marcha (entrevista a Rolando Morán, en Perales 1990: 81)

El EGP continuaba su orientación a la gente, fundamentalmente en la autodefensa. La población que decidió esconderse en la montaña requería ayuda; eran niños, ancianos, enfermos, mujeres y hombres, que tenían que desafiar al ejército como enemigo y al ambiente hostil de la selva. La guerra en Ixcán se había hecho presente, comenzó una etapa de mucho dolor a la vez que un triunfo en la organización civil, ya que se originan las CPR y los campamentos de refugiados:

De parte del EGP también hubo ... sensibilización a la población ... en el sentido de cómo defenderse, en otras palabras, entrenarse un poquito, así toda la gente fue entrenada de una u otra manera, tal vez no llegaron a combatiente pero por lo menos llegaron a saber las partes más elementales de cómo salir corriendo, de cómo identificarse si se quedan perdidos y a un montón de cosas que aprendimos (E-CPR, M. R. 01)

\section{IDEALES REVOLUCIONARIOS Y LIBERADORES INVOLUCRAN A LA POBLACIÓN CAMPESINA}

Cuando comenzaron los contactos de EGP con la población, antes de las masacres de 1981 y 1982, la guerrilla formó cuadros militares que permitían sus actividades organizadas en clandestinidad, esto iba completado con una formación política y de autodefensa en cualquier lugar donde existiese población civil, Payeras (1998: 145) les llama base campesina. El EGP era una organización marxista-leninista, había ciertos principios de la educación fundamentales, como el centralismo democrático, el de la crítica y autocrítica, y la educación y política. 
El movimiento necesitaba ver plasmadas sus ideas en la gente, uno de sus objetivos era conseguir que los pensamientos abstractos de la lucha revolucionaria fueran visibles en sus vidas. Tanto en Ixcán como en la Sierra ${ }^{15}$ u otras partes de Guatemala, vivir con la población campesina era estar frente a frente con la pobreza y la injusticia social, una vivencia que mantuvieron plenamente con las CPR. Asimismo, las CPR de Ixcán tenían una fuerte consolidación y solidaridad, visible en su efectividad en funciones tales como correo, logística, juntas directivas, responsables de grupos, asambleas, etc. Amanda Carreras y Mario Domínguez contrastan el socialismo guerrillero con la vivencia durante el conflicto:

La gente inventó formas para sobrevivir, como en aquel momento había más espíritu de cuerpo y solidaridad, en el Ixcán tuvieron más vida colectiva ... «germen del socialismo», a mí me da pena oírlo, ellos tenían como muy apropiado las ideas de crear una sociedad igualitaria. El discurso no era tan fuerte pero se seguía sintiendo como un germen de comunidad socialista ... Eso no es posible ya en la legalidad, no se puede construir algo así en un mar como éste (E-EGP A. C. 00).

Pienso que afianza valores humanos en primer lugar, hace mucho más fuerte al ver las capacidades que tiene un pueblo en resistir sanos y sacrificar su rato para ir a reuniones, dejar a las familias buscando solidaridad para la comunidad (E- EGP M. D. 00).

Le Bot (1995) asiente que EGP se aprovechó de una base social indígena utilizándola como estrategia de guerra para conseguir los objetivos revolucionarios. Primero utilizaron la «estrategia del foco» en el sentido de potenciar «un núcleo armado, móvil, relativamente autónomo ... su meta esencial: ...la toma del poder del Estado» (Le Bot 1995: 116), después se van apartando del foquismo abierto para captar el movimiento social, fomentar la lucha de clases y preparar la insurrección hacia la guerra de guerrillas. Fernández (1988: 369) admite que «La guerra revolucionaria no puede concebirse sin la participación masiva de la población», desde acciones militares — guerrilleras, paramilitares-, de autodefensa o de actividades relacionadas con la economía de la guerra, la logística. Según Rolando Morán, comandante en jefe de EGP, admite que la contradicción étnica-nacional no puede 
resolverse sino en el marco de la contradicción de clase, e implica a la alianza obrero campesina como complemento a la unidad indígena-ladina.

La intención no llegó a una praxis real, un ejemplo puede observarse en cómo los indígenas no adquirieron cargos de relevancia dentro de la guerrilla, por lo que ha sido considerada una lucha utilitarista de la población indígena, pero que por factores de la propia dirección, dificultades de necesidades educativas y cuestiones estratégicas, no pudo darse una participación equitativa entre ladinos e indígenas, y mucho menos entre hombres y mujeres. En la realidad del conflicto bélico y por la ideología que perseguía el EGP, se fue trabajando en la incorporación de la población indígena campesina, pero la cuestión en sí indígena quedó relegada hasta consideraciones más futuras, como también ocurrió con el trabajo de perspectiva de género.

\footnotetext{
Lo militar lo manejaba otra estructura, la jefatura de columna, donde su estructura militar era más grande, puros chavos; alguna fue capitana, teniente, pero ellas no tenían tropas, sólo de apoyo logístico, no había una capitana con tropa a su nombre, una diferencia sustancial ... A lo que más llegamos fue a abordar la situación de las mujeres en nuestro grupo de mujeres, donde coincidíamos (E-EGP A. C. 00)
}

Pero en este artículo se van a vislumbrar algunos frutos de las ideologías marxistas en manos de la población indígena.

\begin{abstract}
La incorporación de las etnias a la revolución y a una nueva Guatemala no sería un hecho posterior a la reforma agraria, sino exactamente lo contrario, la revolución en Guatemala no era posible sin la participación activa y masiva de los indígenas. No solamente por el aspecto numérico, ya que son la mayoría del país, sino porque la revolución sólo se podía concebir alrededor de dos problemas fundamentales: la lucha de clases y la opresión nacional (entrevista a Rolando Morán, en Perales 1990:70)
\end{abstract}

Las ideologías revolucionarias y liberadoras no fueron responsabilidad solamente de la guerrilla. El involucramiento de la teología de la liberación, que emprendieron en primer lugar jesuitas, acompañó procesos de conciencia de identidades y de lucha por la justicia 
social referidos a mucha población campesina e indígena. Las labores de la Acción Católica, ${ }^{16}$ íntimamente relacionada con $\mathrm{CUC},{ }^{17}$ cambiaron tras incorporar en su lucha una inspiración de la justicia en la opción por los pobres, en un momento que caracteriza a toda América Latina con las conferencias en Medellín (1968) y Puebla (1978) del Concilio Vaticano II. La Iglesia católica, fundamentalmente en El Quiché, se convirtió en el despertar de conciencias especialmente de la población más deprimida, la cual, tras un trabajo de base como formación, protestas, marchas y encierros, se iba manifestando. En Ixcán, el apoyo de la Iglesia católica fue muy importante en la creación de cooperativas, lo que apropió a la población de cierta autonomía. Todas estas iniciativas provocaron la muerte de muchos líderes comunitarios, catequistas y religiosos, lo que indujo a organizarse fuera del país, como la Iglesia Guatemalteca en el Exilio, IGE. Aun así, continuaron apoyando a la población desde la clandestinidad, colaborando en las cooperativas de Ixcán y posteriormente en las CPR, como población refugiada durante el conflicto bélico, tanto en cuestiones logísticas como sacramentales o de acompañamiento. La autora Ángela Duarte califica de inmensamente fuerte el poder de la Iglesia en los movimientos sociales que surgen, debido a que «su discurso es un marco de referencia plenamente incorporado al sentido común, con una autoridad moral prácticamente incuestionable» (Duarte 2008: 285).

\section{LA POBLACIÓN ORGANIZADA CREA UNA NUEVA IDENTIDAD COLECTIVA}

El interés de este estudio surgió por la inquietud de conocer cómo esta población se encontraba tan óptimamente organizada. Para ello tuve que hacer un análisis histórico de Ixcán y del país con el que ver posibles referencias existentes en EGP, Iglesia católica y ONG o personas solidarias. Una característica de las CPR es su nivel de organización, si en un principio, durante los años de clandestinidad y resistencia, estaban supeditados a diversas decisiones que tomaba EGP, ahora ellos mismos consolidaron un poder gracias a una estructura compleja y dinámica de la población, que han ido consolidando conforme desarrollaban su comunidad y creaban unas redes internas que la fortificaron frente a lo exógeno. La estructura organizativa de la comunidad actual se basa en la formada durante 
la resistencia. Seguían fundamentalmente las labores organizativas sectoriales - OMR, jóvenes, maestros y otros - y comunitarias - CEPI, Cooperativa.

Todo el trabajo de la comunidad se reparte en jornales invertidos en labores comunitarias; son alrededor de 140 personas, desarrollan tareas por elección o por designación de la comunidad: las burocráticas que hace $\mathrm{CEPI}^{18}$ y la junta directiva de la Cooperativa, como las de los promotores de salud, comadronas, maestros, chóferes, lancheros, tenderos del kaibil, ${ }^{19}$ vaqueros, encargado del motor del agua y de su filtrado y el secretariado. Estos jornales invertidos en la comunidad se traducen en sustitutos de las labores productivas obligatorias que cada asociado a la Cooperativa o miembro de la comunidad debe cumplir. Las horas que tienen para realizar sus tareas dependen del trabajo, están obligados a trabajar dos días en proyectos de la comunidad y un día semanal en las tareas de la comunidad - limpieza, construcción, etc.-, esto depende de las funciones; por ejemplo, los promotores de salud trabajan tres días a la semana, los miembros de CEPI todos los días se reúnen, los maestros de lunes a viernes, y los sábados los dedican a sus parcelas, los chóferes del autobús viajan hasta Cantabal — cabecera municipal— todos los días.

Estas son obligaciones que tienen los miembros de la comunidad, creándose un modelo integrador que de alguna forma es aceptado y elegido en asamblea. Su organización es un modelo que han ido creando desde la resistencia y que actualmente sigue funcionando, su deseo por ser democrática no la aleja de una jerarquización, ya que todo está muy centralizado por las decisiones que toma CEPI.

Durante la organización clandestina, para sobrevivir de la mejor forma posible se apoyan de sus procesos organizativos previos en las cooperativas como en sus comunidades natales, o también dependiendo de las organizaciones donde hubiesen participado. En las cooperativas retomaron cuestiones más colectivas y democráticas, tomando la asamblea general como principal motor decisivo y de participación política, junto a los quehaceres cotidianos de educación, salud, logística, entre otros, reforzado con la teología de la liberación. Lo multicultural e intercultural se fue dando al unirse pueblos mayas junto a ladinos, donde se niega la diferenciación étnica para favorecer un estado de heterogeneidad 
cultural como considera la corriente multiculturalista de la autora Manuela Camus (2002), observable en las cooperativas de Ixcán, ya que en su espacio físico colonizaron un nuevo territorio donde se desarrolló este proceso al convivir diferentes pueblos indígenas ${ }^{20}$ del propio país, que revierten en sociedades colectivas y construidas (Melucci 1995). Reafirman su identidad étnica desde una reinvención cultural, generando culturas híbridas que García Canclini (2001: 331 ss) describe como desafiante a la concepción conservadora del concepto de identidad: «La afirmación de lo regional o nacional ... la capacidad de interactuar con las múltiples ofertas simbólicas internacionales desde posiciones propias», y se refiere a culturas que han sido modificadas y rediseñadas tanto desde relaciones intraculturales como añadiendo elementos extraculturales, que luego han sido acuñados o etnificados como propios. Camus (2002: 44) alega que las interacciones entre tantos factores, como «información, comunicación y fusiones culturales», tiende a ocultar estructuras de poder y asimetría, donde puede estar implícita la «trascripción oculta» que señala Scott (1990) y Colburn (1989), en los grupos subalternos y su propia dominación en sus espacios. Así, en las CPR de Ixcán se observa dentro de la cotidianidad esos referentes subalternos, potenciado hacia las mujeres; aunque sus participaciones y decisiones han variado dependiendo del momento, ellas tienen más participación en las situaciones de más crisis. $^{21}$

Para visibilizar los sectores de la comunidad más subalternos, de hecho destaco a las mujeres de las CPR del Ixcán. Ellas han protagonizado un desarrollo en cuanto a conciencia de género apoyado directamente por mujeres de EGP, que con su propia voluntad generaron proyectos productivos para encontrar apoyo familiar, y posteriormente ir transcendiendo hacia la conciencia de género, aunque sufrieron un traslado de roles de responsabilidad comunitarios que ganaron durante la resistencia, donde su empoderamiento fue permitido por la comunidad. Las mujeres de las CPR tienen una organización, la Organización de Mujeres en Resistencia, OMR, que responde a un feminismo práctico (Castells 1998) o movimiento por la sobrevivencia (González 1998), pero no se salvan de que a través de la politización de lo cotidiano, es posible articular demandas complejas (Duarte 2008: 274). No siempre la identidad de género ha sido el 
motor de la movilización de las mujeres, «esta identidad es compleja», como define Molyneux (2003: 235), ni siquiera primordial o única.

Las mujeres son protagonistas junto con otros sectores de población de la subalternidad, su espíritu y valentía son potencialmente revolucionarios, de ahí que Sundarayya (1972: 328) destaque el espíritu y energía revolucionaria latente en las mujeres, solo que habría que «ayudar a que saliera del caparazón de las costumbres tradicionales». En sí, el activismo es fruto de situaciones de crisis, ya que los conflictos pueden servir para convertir a las mujeres en agentes de desarrollo (Cagán y Juliá 1998), aunque en muchas ocasiones la mujer se instrumentaliza, como puede verse en los movimientos guerrilleros (Chinchilla 1994). En momentos de conflicto, según Diamont (2000), las mujeres han podido demostrar en ausencia de hombres cómo pueden tener cargos de responsabilidad, pero que por los estereotipos de las desigualdades de género sus acciones se vieron trasladadas del espacio público ocasionalmente y después al espacio privado de nuevo (Paterna y Martínez 2004).

Está bien que siga OMR para que no sea en balde la lucha de todas las mujeres, yo pienso que sigan. Siempre hay problemas, a la hora de un trabajo no llegan, se niegan, todas no están decisivas de hacer una reunión ... Lo que no hagamos ahora, no estará para después, si dejamos nuestra organización, lo que pudimos conseguir desaparecerá, y ahora mejor es mantenernos e intentar mejorar y conseguir lo que aún no pudimos (E-CPR M. H. 01).

En cuanto a los jóvenes de las CPR del Ixcán, están sufriendo muchos cambios, pero se incorporan a proyectos estratégicos, participan en la organización comunitaria, y poco a poco toman responsabilidades, como en la cooperativa, en el comité ejecutivo... junto a la formación de maestros y promotores de salud con el fin de apoyar a su propia comunidad. El estudio es valorado aunque también existe la búsqueda de otro futuro fuera del proyecto comunitario, emigrando incluso a EEUU.

El apoyo que venía del exterior comenzó desde IGE; fue la primera organización que se interesó por las personas que no habían salido al refugio y quedaron bajo la montaña, pero actuaron de una forma más organizada a partir de 1986 e inicios de 1987, coincidiendo 
con la época de más tranquilidad y cambios. Cuando la situación se normalizó, se creó un intermediario con la Acción Católica desde 1986, su función era de trasmisor de la realidad de la población, se hacía conjuntamente con población refugiada: «Se organizaban actividades religiosas y se empezó una serie de talleres, informaciones en México para las necesidades de las CPR» (E-CPR M. Baltasar, 01).

\footnotetext{
A finales del 84 fue cuando empezamos a recibir las primeras ayudas, con los centavos, este comité que velaba por todos los grupos empezamos la compra de recursos para la gente: calzados, o sea botas, ropa, sal, jabón, medicina, que para nosotros era lo prioritario; bueno, claro, molinos de nixtamal de mano ... otras necesidades se podían aguantar, verdad. Se empezó a comprar y a distribuir a cada grupo (E-CPR M. Ramírez, 01)
}

Todo el funcionamiento de la pastoral de guerra estaba aprobado por el obispo y la guerrilla; junto con la coordinación del Comité de Pobladores del Ixcán, CPI, el EGP posibilitaba el contacto con el exterior, para proveerse de los materiales necesarios y tener información mediante el correo; una función de considerable importancia y peligrosidad. Falla entendió la «justificación del trabajo pastoral» por el «Derecho de la población civil en su opción revolucionaria a ser acompañada por el servicio pastoral de la Iglesia a la que pertenecen» (Falla 1992: 15).

La población desde las cooperativas obtuvo influencias de las fuerzas revolucionarias, las religiosas, junto a las propias estrategias comunitarias orientadas por las tradiciones mayas. ${ }^{22}$ Por tanto, converge un vínculo religioso y revolucionario en la identidad colectiva, sumando la ideología guevarista en pro o en defensa de una «guerra justa» (Bobbio 2000) y liberadora. Tilly también abarca la interacción con los diferentes protagonistas sociales: «... los movimientos [son] como desafíos colectivos planteados por personas que comparten objetivos comunes y solidaridad en una interacción mantenida con las elites, los oponentes y las autoridades» (1986: 4), y que se unifican en la lucha contra el poder opresor confiriendo un carácter compartido de «pueblo-nación» (Vilas 1989: 57 ss); pero Touraine (2005: 194) se inspira en que cada movimiento siembra «figuras de derecho», las cuales pueden y deben imponerse en cualquier situación. 
En cuanto a la cosmovisión maya, ${ }^{23}$ destaco la «resistencia pacífica» (Adams 1991: 132), cuya preocupación fundamental ha sido la de «sobrevivir en un ambiente natural fuertemente degradado por fuerzas políticas y económicas», que están muy lejos de su control, denominándose población civil no armada. Bastos y Camus (Adams y Bastos 2003: $368)^{24}$ cercioran que existe una «identidad "panindígena", que combina una identificación de base comunitaria con una vivencia entre indígenas de diferentes orígenes», aumentado por la unificación de población víctima de la represión militar - refugiados, desmovilizados y población en resistencia- Su objetivo es «subsistir» —o resistir- como indígenas y no ser destruidos por las sociedades extranjeras y petroleras ni por el ejército. Asimismo, el «Pueblo guatemalteco ha heredado el espíritu de lucha y resistencia que nos dejaron nuestros antepasados»(URNG 1995: $10 \mathrm{ss}$ ), herencia que se concreta hoy en las luchas y negociaciones que siguen avanzando hacia la construcción de una «nueva» Guatemala.

La mayoría de personas que se relacionó con las CPR, muchas europeas, porque «América es —al mismo tiempo- depositaria de la esperanza perdida en Europa» (Ainsa 1997: 164), ha provocado sueños compartidos, una especie de socialismo utópico y espejismo socialista que interrelaciona los valores de «Resistencia para Avanzar», que conduce hacia un desarrollo comunitario propio, con valores de solidaridad y justicia que revierten en identidades estratégicas por su participación política pública (Cohen y Arato 2000). La siguiente ilustración muestra la interconexión de la identidad de las CPR de Ixcán desde sus propias inherencias junto a caracterizaciones exteriores:

Ilustración 2. Representación de la etnogénesis de las CPR de Ixcán 
Muñoz Sánchez, Práxedes

«De la violencia surge una cultura política de resistencia

- las CPR del Ixcán - que deriva en una participación

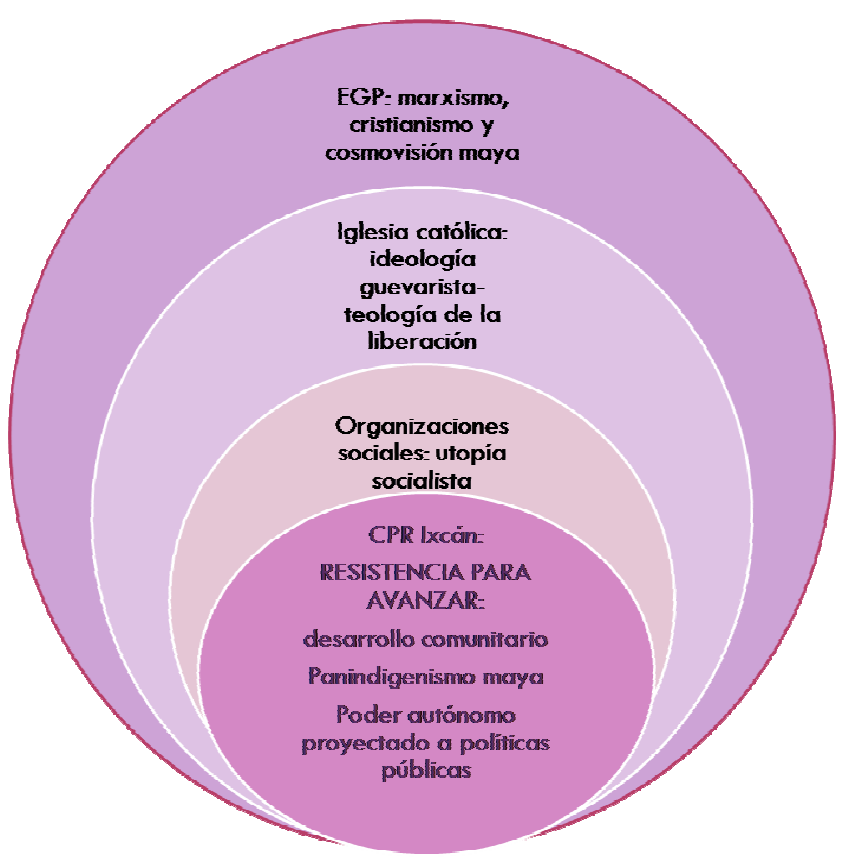




\section{HACIA POLÍTICAS MUNICIPALES Y CONSIDERACIONES POLÍTICAS PARA EL HOY}

Tras los Acuerdos de Paz de Guatemala, las actuaciones políticas de la población subalterna, fundamentalmente indígena, y la experiencia durante la resistencia en el conflicto armado interno, han fomentado la preocupación por desarrollar óptimas políticas municipales que fortifiquen a la ciudadanía, como la realización de consultas populares legales. En Ixcán, quiero destacar la presentación en la alcaldía municipalidad de Marcos Ramírez Vargas, ${ }^{25}$ quien fue elegido en dos legislaturas, de 1999 a 2007. Marcos pertenece al pueblo mam y es miembro de las CPR del Ixcán; sobresalió como muchos otros en sus acciones, principalmente en los comités ejecutivos - CPI, CEPI y CCPI- de las CPR, y fuera de la comunidad en la Asociación Consultiva de la Población Desarraigada, ACPD. Como mujer en acciones de políticas municipales y con experiencias similares destacamos a Carmelita Ross, ${ }^{26}$ quien fue miembro igualmente de CPI en las CPR, y que tras su reasentamiento en la comunidad de Chimaltenango participó activamente en las cooperativas de vivienda para desmovilizados. Asimismo, en Primavera del Ixcán, perduran importantes cuadros políticos que fueron formados durante la resistencia en distintas áreas: DDHH, salud, educación, etc. Aunque muchos de ellos no pertenecían a la guerrilla, sigue existiendo mucha población en las CPR que sí creen en su discurso político, además de que son partícipes, como se vio en campañas de propaganda y formación a líderes comunitarios. Tal es el caso de Lorenzo Choc, «él es de los pocos que habla q'eqchí y podía hacer charlas en comunidades q’eqchíes de Ixcán; pertenecía al Equipo de Trabajo Pastoral, lo cual le daba un prestigio y un acercamiento a los sectores de la Iglesia católica» (E-CPR L. C. 01).

La organización comunitaria de las CPR del Ixcán creó una identidad desde la cultura política de la resistencia que actualmente sigue existiendo. Su deseo por ser democrática no la aleja de una jerarquización, muy centralizada en las decisiones que toma el comité ejecutivo pero con el órgano mayor de la asamblea comunitaria. ${ }^{27} \mathrm{El}$ organigrama contiene también los sectores internos: cooperativa, alcalde auxiliar, maestros, promotores de salud, OMR, viudas, ETP, evangélicos y jóvenes. Además de los servicios en la comunidad, como producción, seguridad, proyectos, educación, salud, etc. Su participación política no ha 
quedado reducida al ámbito comunitario, sino que las CPR del Ixcán han contemplado la importancia de las acciones estatales para poder ser escuchadas y tener apoyos de distintos ámbitos. Sin hacer un estudio de los logros y dificultades que han existido en los últimos años, es evidente que dentro de un sistema donde los subalternos hacen su llamado mostrando estrategias aprendidas, junto a los propios indígenas, y los múltiples condicionantes que surgieron en las CPR del Ixcán; la organización va adoptando diferentes instrumentos, ahora es la cuestión cultural e indígena la que permite un mayor reconocimiento de su cultura y sus derechos. Se ha alimentado de múltiples fuerzas, y actualmente la mayoría confía en el programa de URNG, muchos están afiliados al partido, otros participan activamente en la Pastoral Social de Ixcán y/o trabajan en ONG o programas de desarrollo, y se ha dado el caso de participaciones en la municipalidad.

Un testimonio de Miguel Ángel Sandoval ${ }^{28}$ — candidato a la presidencia del partido URNG-MAIZ $^{29}$ en 2008 - valora el poder local de las CPR, que se apoyan desde la municipalidad como «el primer paso para conseguir la realización de las demandas históricas de esta población. De cierta forma, para las CPR se trata de dejar de esperar con paciencia franciscana que las autoridades del país se acuerden de ellas, y ahora dicen: "es nuestro tiempo pues ya estamos hartos de tanto engaño, tanta promesa falsa y tantas largas a nuestras demandas"». Sobre la acción comprometida de las CPR con URNG-MAÍZ subraya que ésta va más allá de lo electoral, porque considera que la llama de la resistencia popular se encuentra viva en muchos lugares del país y la necesidad de victorias sociales o políticas se siente con urgencia. Gilly (2006: 92) considera que es importante «escuchar las voces subalternas» que yacen detrás de las de «actores principales», teniendo en cuenta que suelen ser «las de otros protagonistas con maneras y derechos propios».

En cuestión de las políticas de URNG, aunque unificaba los asuntos sociales en razones de lucha de clases «Dentro de estas organizaciones [que forman URNG] el debate sobre la cuestión étnica y su participación como indígenas es secundario, y a su interior se reproduce la diferenciación étnica que hay en el país» (Bastos y Camus 2003: 23), en procesos posteriores parte del movimiento maya ha estado vinculado a URNG. Las organizaciones que han mantenido una relación directa con EGP han sido: la Coordinadora 
Nacional de Viudas de Guatemala, CONAVIGUA; el Consejo Nacional de Desplazados de Guatemala, CONDEG; las Comisiones Permanentes de Refugiados en México, CCPP, y las Comunidades de Población en Resistencia, CPR (Bastos y Camus 2003).

Entre 1992 y 1993 se produjeron diferencias y rupturas entre organizaciones vinculadas a EGP y ésta, principalmente por la forma de cómo llevar las cuestiones de hacer política con el gobierno; no querían negociar con el gobierno: «La autonomía de acción con que contaban respecto al núcleo político-militar no fue suficiente para lo que algunas organizaciones reclamaban» (Bastos y Camus 2003: 29). Ante estas diferencias, aquí destacamos el vínculo permanente de las CPR del Ixcán con URNG, siendo mayor con los integrantes de lo que fue EGP. Una de las causas puede estar relacionada con mantener la forma de «organizaciones populares» que provenía de la tradición de movilización de los años 70. «Se basaban en un fuerte liderazgo nacional y una membresía por adhesión ideológica entre personas y organizaciones de base, y su objetivo principal era la actuación en la arena política a nivel nacional» (Bastos y Camus 2003: 77), centrándose en sus principales problemas: tierra, pobreza y violación de los derechos humanos, provocando espacios políticos a la vez que una cultura política originada en la resistencia de la violencia del ejército gubernamental, armándolos de nuevos instrumentos políticos muy válidos; $\mathrm{y}$ que han podido trasgredir en fuerza política para el movimiento maya e indígena, como cercioran Bastos y Camus (2003: 79): «Así, el movimiento revolucionario irá proveyendo de líderes, organizaciones, y al final de fuerza política al movimiento maya».

En la campaña de propaganda electoral del año 1999, llegó a Primavera del Ixcán una visita de Álvaro Colom, actualmente presidente de la República de Guatemala, quien se presentaba como candidato del partido Alianza Nueva Nación, ANA, coalición DIA/URNG. ${ }^{30}$ Fue un acto de gran importancia y honor para Primavera del Ixcán, con especial atención porque Marcos Ramírez se presentaba por primera vez como alcalde del municipio de Playa Grande. En la ilustración siguiente enfatizo sobre la frase dedicada a Marcos Ramírez: «¡Porque Marcos entiende al Pueblo!», este mensaje trasciende desde la resistencia; las CPR conocen la dureza del conflicto, entienden a la población indígena y 
creen en un espacio de conexión entre su partido y las intendencias del gobierno y organizaciones indígenas e internacionales.

Pero en el 2000, ocurrió algo que dio una luz de esperanza al proceso: asumió la alcaldía municipal un representante de las Comunidades de Población en Resistencia, CPR, y fue desde ahí que se empezó a escribir otra parte de la Historia (SERJUS 2009:36)

Ilustración 3: Pancartas por la visita de Álvaro Colom a Primavera del Ixcán, agosto 1999

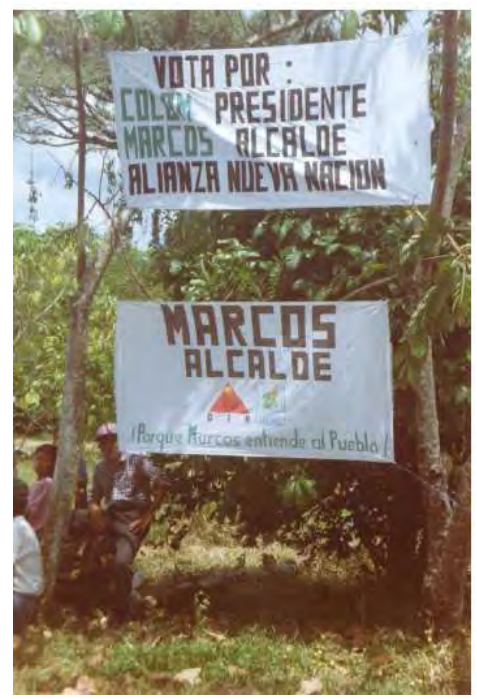

Fotografía de la autora.

En la alcaldía de Marcos Ramírez se observa una actuación estratégica, donde la población indígena está siendo partícipe dentro del programa electoral de URNG, ${ }^{31}$ porque se prioriza sobre la formación de la población, especialmente de las autoridades, con el fin de descentralizar los poderes estatales y representar a las comunidades indígenas y a la población campesina, la mayoría en situación de pobreza: «El desarrollo debe empezar de abajo hacia arriba. Esta ha sido nuestra ideología, por lo que tratamos de fortalecer a las autoridades comunitarias con talleres de capacitación» ${ }^{32}$.

En Primavera del Ixcán hay activismo en casi todos los sectores, así como presencia en las demandas a la municipalidad, donde firman protestas, acuerdos, etc., tanto de la comunidad en general como en particular de parte de la Cooperativa La Resistencia, la 
Organización de Mujeres en Resistencia, OMR, de la Pastoral Social, la Asociación de Maestros y de la Red de Derechos Humanos de Ixcán. ${ }^{33}$

En cuanto al ex alcalde municipal de Ixcán, Marcos Ramírez, quien ha tenido que enfrentarse a diversas amenazas tanto hacia su persona como a varios de sus proyectos políticos $^{34}$ desde los sectores conservadores del país; sus acciones no cesaron, de ahí que persiga un proyecto político de capacitación con diferentes apoyos externos importantes, donde participan: la Pastoral Social, Misión de Verificación de las Naciones Unidas, MINUGUA, y la organización civil Asociación de Desarrollo Comunitario SIEMBRA. ${ }^{35}$ Los adversos acusan al señor Ramírez Vargas de estar asesorado por comandantes guerrilleros. Se conoce que estas acusaciones no tienen ningún fundamento y solamente pretenden manipular y esconder la verdad acerca de otros delitos cometidos por algunos de los dirigentes de este grupo que no acepta el resultado democrático de las elecciones. ${ }^{36}$

Es evidente que en Ixcán han revelado una identidad que surge en la colonización de la década de los 60 , cuando emergen múltiples culturas, calificándose de un municipio multicultural y multilingüe; el municipio de Ixcán corrobora que «convivimos comunidades de once pueblos mayas y ladinos», comentado en El Encuentro Binacional sobre los Tratados Comerciales y la Selva de Ixcán, ${ }^{37}$ en el municipio de Ixcán, durante los días 27 y 28 de junio de 2003 a iniciativa de la municipalidad y en coordinación con organizaciones locales, que tras analizar el contenido y el impacto de los TLC en los ámbitos político, económico, sociocultural y medioambiental, pronunciaron conclusiones en defensa de los pueblos indígenas. Por tanto se observa una lucha panindígena que incluye población ladina, ya que su delimitación cultural proviene más de los procesos históricos, o como dice Villoro (2003: 37), apostar por la creación entre todos de la comunidad renovada en una «libertad de realización para todos».

La Consulta Comunitaria de Buena Fe, realizada en el municipio de Ixcán el 22 de abril de 2007, ha sido un ejemplo de participación para todo el país. Fue organizada por las autoridades del municipio de Ixcán para someter a consulta la realización de megaproyectos, tales como construcción de represas sobre los ríos de Ixcán y explotaciones petroleras en el marco del Plan Puebla Panamá (SERJUS 2009). La participación fue 
masiva y $90 \%$ votó No, con una abstención de $2 \%$, «por lo que en palabras de Marcos Ramírez, alcalde de Ixcán, es una consulta "representativa y vinculante"» (Caballeros 2007) ${ }^{38}$. Fue criticada como una postura contra el desarrollo, pero Marcos Ramírez aclaró que «no aceptan el proyecto de construcción de Xalalá por la forma en que ha sido planteado» ${ }^{39}$, es decir, sin considerar las opiniones de las comunidades donde se quieren realizar estos proyectos, basándose en experiencias de otras comunidades por el peligro de no valorar los impactos sociales y ecológicos.

Han optado por realizar consultas comunitarias y decisivas en políticas de acción, donde siguen apoyándose en observaciones nacionales e internacionales, para con ello crear esperanza en los pueblos más reprimidos, constituyéndose en «un ejemplo de resistencia y lucha por construir un mundo más humano y solidario para todos» (SERJUS 2009: 20). Igualmente así lo recoge la Comisión Pastoral Paz y Ecología: «Al mismo tiempo son una lección para las autoridades nacionales, que piensan poder determinar el futuro de este país sin buscar un consenso con los habitantes de este país» (COPAE 2007).

Asimismo, la municipalidad apoya su proyecto político mediante la creación de organismos representativos que descentralicen la política gubernamental, como es el caso de la Mancomunidad de Municipios Frontera del Norte. Marcos Ramírez admite que al organizar sectores se «rescataría parte del poder local, ya que el sistema gubernamental actual es de modelo centralista, lo que ha sido una barrera para la ejecución de proyectos municipales» $^{40}$.

Esta municipalidad ha buscado una representatividad de los colectivos más subalternos, encontrando apoyos en ONG, sectores de la Iglesia católica, junto a su partido político. También son de destacar sus experiencias comunitarias, mismas que han dado fruto en políticas más públicas, preocupada por la formación de la población. SERJUS (2009) cerciora que el éxito de estas estrategias se debe a un fortalecimiento de la unidad de las demandas comunitarias, apoyándose en redes sociales interesadas por el devenir de la población: 
Entre los factores internos, podemos destacar la voluntad política del gobierno municipal de Izquierda, que ha favorecido la participación de la población y ha fortalecido los espacios de información e intercambio de experiencias. Entre los factores externos, que paradójicamente han favorecido al proceso, podemos mencionar: la implementación de las políticas neoliberales -sin un procedimiento de información ni consentimiento de parte de la población- pues ha contribuido a que la gente pueda identificar a sus rivales en común; los empresarios y el gobierno (SERJUS 2009: 46).

Ilustración 4. Asamblea comunitaria de Primavera del Ixcán, Sector II. Agosto 1999

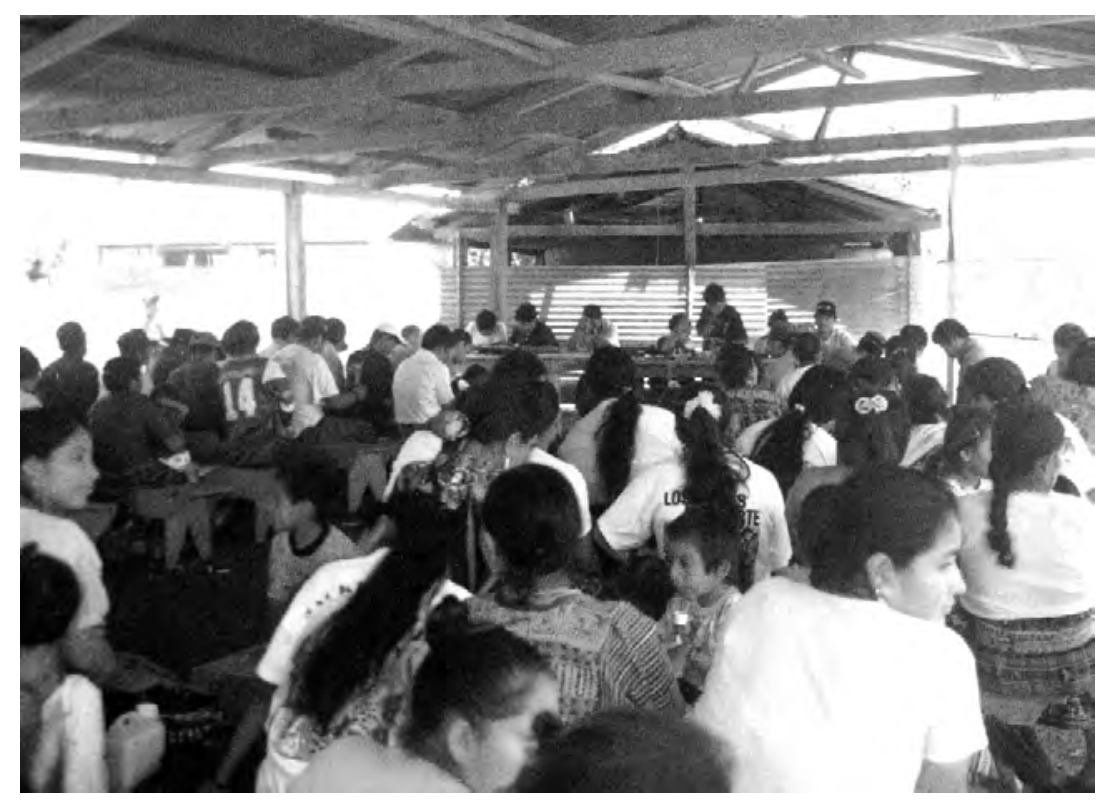

Por último, en la «Declaración de las comunidades y organizaciones sociales de Ixcán con motivo del día mundial de los pueblos indígenas en defensa de la tierra y los recursos naturales» (Ixcán, 9 de agosto de 2008), se puede corroborar que la población indígena del Ixcán está pendiente de las cuestiones políticas y culturales, las amenazas a sus tierras y las consecuencias de las políticas municipalistas.

\section{CONCLUSIÓN}

Tras una revisión de la identidad colectiva de las CPR del Ixcán, se observan los motivos que generan resistencias originadas en un ambiente de guerra. Estas estrategias nacen de la unión y la retroalimetación de los agentes mencionados, comunidad de campesinos 
— población indígena y ladina—, guerrilla, religiosos seguidores de la teología de la liberación y ONG y asociaciones que les mueve implicaciones ideológicas y de justicia. Y valga decir que no han sido en balde todos los apoyos o relaciones que mantuvieron con la población organizada en resistencia, pues en la actualidad siguen luchando y fortaleciendo participaciones políticas, reuniendo así a subalternos provocadores del cambio para la autoformación y conciencia desde la descentralización por la que apuestan, buscando el reconocimiento cultural indígena como un nuevo instrumento antes olvidado pero que ahora está encontrando un espacio de autoconocimiento y valoración.

A la vez, quienes han estado en el otro lado, observando y apoyando a sectores subalternos, se llevan una infinidad de valores imposibles de vivir en sus sociedades actuales, alimentando el socialismo utópico que intensificó sus vidas. Esta visión puede crear interrogantes siempre sobre ¿qué hubiera pasado si no contaran con los apoyos mutuos? Es imposible contestar, la identidad individual y colectiva está sumida en un sinfín de relaciones y referencias que caracterizan singularidades de cada persona, que según el proceso histórico y la significación que tenga, será de una forma u otra, dependiendo del momento y libertad de cada individuo y colectivo. 


\section{BIBLIOGRAFÍA}

Adams, Richard, 1991, «Conclusiones: ¿Qué se puede saber sobre la cosecha de violencia?». En Guatemala: Cosechas de violencia, compilado por Richard Carmack, pp. 447-452. FLACSO, San José, Costa Rica.

Adams, Richard y Santiago Bastos, 2003, Las relaciones étnicas en Guatemala, 1944-2000, tomo II. CIRMA, Guatemala.

Ainsa, Fernando, 1997, La reconstrucción de la utopía. UNESCO, México.

AVANCSO, 1992, ¿Dónde está el futuro? Procesos de reintegración en comunidades de retornados. AVANCSO, Guatemala.

Bobbio, Norberto, 2000, El problema de la guerra y las vías de la paz. Gedisa, Barcelona ( $1^{\text {a }}$ edición 1979).

Bastos, Santiago y Manuela Camus, 2003, El movimiento maya en perspectiva: Texto para reflexión y debate. FLACSO, Guatemala.

Cagán, Beth y María Juliá, 1998. «Maintaining wartime gains for women: Lessons from El Salvador». International Social Work, núm. 41, pp. 405-415.

Camus, Manuela, 2002, Ser indígena en Ciudad de Guatemala. FLACSO, Guatemala.

Castells, Manuel, 1998, La era de la información. Economía, sociedad y cultura, vol. II. Alianza Editorial, Madrid.

CEH, 1999, Guatemala Memoria del Silencio. Comisión para el Esclarecimiento Histórico, Guatemala. 
Chinchilla, Norma Stolz, 1994, «Women's movements, feminist movements, political parties and the state». En Women and the transition to democracy: The impact of political and Economic reform in Latin America, editado por J. Jaquette, N. Chinchilla, M. Criment y M. Buvinic, pp. 12-19. The Wodrow Wilson Center, Washington, D. C.

Cifuentes, Juan Fernando, 1982, «Operación ixil». Revista Militar, núm. 27, pp. 25-72. Guatemala.

Cohen, Jean L. y Andrew Arato, 2000, Sociedad Civil y teoría política. Fondo de Cultura Económica, México.

Colburn, Forrest D. 1989, «Introduction». En Everyday Forms of Peasant Resistance, editado por Forrest D. Colburn, pp. ix-xv. M. E. Sharpe, Armonk.

Diamont, Hanna, 2000, «A new dawn? French women and the liberation». Women's Studies International Forum, vol. 6, núm. 23, pp. 729-738.

Dietz, Gunther, 1999, La comunidad Purhépecha es nuestra fuerza. Etnicidad, cultura y religión en los movimientos indígenas en México. ABYA YALA, Ecuador.

2003, Multiculturalismo, Interculturalidad y Educación: Una aproximación antropológica. Universidad de Granada, Granada.

Duarte, Ángela Ixkic, 2008, «Género y procesos organizativos de las mujeres nahuas del sur de Veracruz». En Estudios sobre cultura, género y violencia contra las mujeres, editado por Roberto Castro e Irene Casique, pp. 261-290. UNAM, México. 
Falla, Ricardo, 1992, Masacres de la selva. Ixcán, Guatemala (1975-1982). Editorial Universitaria, Guatemala.

Fernández, José Manuel, 1988, «Comunidades Indígenas y conflicto social en Guatemala». Tesis doctoral. Universidad Complutense de Madrid, Madrid.

García Canclini, Néstor, 2001, Culturas hibridas: estrategias para entrar y salir de la modernidad. Paidós, Buenos Aires.

Gaudenzi, J., 1992, «Destino Ixcán: perfil de una de las áreas de retorno de los guatemaltecos refugiados en México». Manuscrito inédito.

Gilly, Adolfo, 2000, El siglo del relámpago. Siete ensayos sobre el siglo XX. Itaca, La Jornada, México.

2006, Historia a contrapelo. Una constelación. Ediciones Era, México.

González, José y Antonio Campos, 1983, Guatemala. Un pueblo en lucha (colaboración Eduardo Galeano). Revolución, Madrid.

González Luna, Lola, 1989-90, «Género y Movimientos Sociales en América Latina». Boletín Americanista, núm. 39-40, pp. 131-141. Barcelona.

IGE, 1989, Guatemala: seguridad, desarrollo y democracia. IGE, México.

Kuper, Adam, 2001, Cultura. La versión de los antropólogos. Paidós Básica, Barcelona.

Le Bot, Yvon, 1995, La guerra en tierras mayas. Comunidad, violencia y modernidad en Guatemala (1970-1992). Fondo de Cultura Económica, París. 
López de Ceballos, Paloma, 1989, Método para la investigación. Una Acción participativa. Editorial Popular, Madrid.

Luján, Jorge, 1998, Breve Historia contemporánea de Guatemala. Fondo de Cultura Económica, México.

Melucci, Alberto, 1995, «The New Social Movements Revisited: reflections on a sociological misunderstanding». En Social Movements and Social Classes: the future of collective action, editado por Louis Maheu, pp. 107-119. SAGE, London.

Molyneux, Maxine, 2003, Movimiento de mujeres en América Latina. Editorial Cátedra, Madrid.

Montes del Castillo, Ángel, 2000, «Antropología, investigación acción y trabajo social». En Para el trabajo social, aportaciones teóricas y prácticas, coordinado por M. ${ }^{\mathrm{a}} \mathrm{J}$. Martínez, pp. 197-238. Maristán, Granada.

Morales, Mario Roberto, 1998, Los que se fueron por la libre. Editorial Praxis, Guatemala.

ODHAG-REHMI, 1998, Guatemala: Nunca Más (versión resumida). Hirugarren Prentsa, Guatemala.

Olson, Mancur, 1971, The logic of Collective Action: public goods and the theory of groups. Cambridge, MA. 
Paterna, Consuelo y Carmen Martínez, 2004, «La perspectiva de género en la resolución de conflictos: una aportación desde la Psicología Social». En II Congreso Nacional Universidad y Cooperación al Desarrollo. Instituto Universitario de Cooperación al Desarrollo, Universidad de Murcia, Murcia.

Payeras, Mario, 1998 [1981], Los días de la selva. Piedra Santa, Guatemala.

Perales, Iosu, 1990, Guatemala Insurrecta. Entrevista con el Comandante en Jefe del Ejército Guerrillero de los Pobres, por Iosu Perales. Editorial Revolución, Madrid.

Piel, Jean, 1997, «Quichelandia: ocho siglos de historia de una frontera interna que nunca fue definitivamente integrada a Guatemala». En Las Fronteras del Istmo: Fronteras y Sociedades entre el sur de México y América Central, editado por Philips Bovin, pp. 135-152. CEMCA, México.

Ribeiro, Darcy, 1984, El dilema de América Latina. Siglo XXI, México.

Rosada, Héctor, 1999, Soldados en el poder: Proyecto Militar en Guatemala (1944-1990). Funpadem, Universidad de Utrecht Holanda, Costa Rica.

Rostica, Julieta, 2003, «Surgimiento del movimiento maya en los años noventa: una aproximación comparativa a Guatemala y México». En e-l@tina. Revista electrónica de estudios latinoamericanos, vol. 2, núm. 5, pp. 31-50, Buenos Aires. http://www.catedras.fsoc.uba.ar/udishal [consultado el 7 de junio de 2006].

Sandoval, Miguel Ángel, 2007 [1981], «Letra con Filo: Reencuentros y evocaciones», septiembre de 2007, Guatemala. En http://www.albedrio.org/htm/articulos/r/rmm027.htm [consultado el 3 de diciembre de 2008]. 
Santos, Carlos, 2007, Guatemala El silencio del gallo. Debate, Barcelona.

Schirmer, Jennifer, 2001, Intimidades del Proyecto político de los militares. FLACSO, Guatemala.

Servicios Jurídicos y Sociales, SERJUS, 2009, «Estrategias para la defensa del territorio y de los recursos naturales». En América Latina: Riqueza privada, pobreza pública, editado por CIDSE y ALAI, pp. 34-49. CIDSE y ALAI, Quito.

Scott, James, C. 1990, Los dominados y el arte de la resistencia. Txalaparta, País Vasco.

Schutter, Antón de, 1987, «Método y proceso de la investigación participativa en la capacitación rural». Cuadernos del CREFAL, núm. 19. CREFAL, Pátzcuaro, Michoacán.

Sosa, Mario Enrique, 2001, «Comunidad y sistema de clasificación étnica». Tesis de maestría. Universidad de San Carlos de Guatemala, Guatemala, Universidad de Oslo, Noruega ( $\sin$ publicar).

Stoll, David, 1993, Between Two Armies in the Ixil Towns of Guatemala. Columbia University Press, Nueva York. Traducción del inglés, 18 de mayo de 1995 (borrador).

Sundarayya, Puccalapalli, 1972, Telengana People's Struggle and Its Lessons. Communist Party of India-Marxist, Calcuta.

Tilly, Charles, 1986, The Contentious French Four Centuries of Population Struggle. Harvard University Press, Cambridge, MA. 
Torres-Rivas, Eduardo, 1996, Encrucijadas e incertezas en la Izquierda Centroamericana: Ensayo preliminar de interpretación. FLACSO, Guatemala.

Touraine, Alain, 1980, «The New Social Movements: A Theoretical Approach». Social Science Information, vol. 2, núm. 19, pp. 199-226.

2005, Un Nuevo paradigma para comprender el mundo de hoy. Paidós, Barcelona.

URNG, 1988, Línea política de los revolucionarios guatemaltecos. Editorial Nuestro Tiempo, México.

1995, El Agitador, núm. 44, Guatemala.

Velasco, Honorio y Ángel Díaz de la Rada, 1997, La lógica de la investigación etnográfica. Trotta, Madrid.

Vilas, Carlos María, 1989, Transición desde el subdesarrollo. Revolución y reforma en la periferia. Nueva Sociedad, Caracas.

Villoro, Luis, 2003, De la libertad a la comunidad. FCE, México.

Wilson, Richard, 1999, Resurgimiento maya en Guatemala (Experiencias Q'eqchi'es). CIRMA, Guatemala.

\section{PÁGINAS ELECTRÓNICAS}

Boletín Semanal de la Plataforma Agraria, año 6, núm.13, semana de 17 a 23 de abril de 2007. En http://www.albedrio.org/htm/articulos/c/ [consultado el 15 de diciembre de 2008]. 
Caballeros, Álvaro, AVANCSO/CENINF, observador de la Consulta en la Comunidad de Xalalá, Ixcán, Guatemala. Con información de Comisión Organizadora y la Asociación Coordinadora Comunitaria de Servicios para la Salud, ACCSS. En http://alainet.org/active/17083\&lang=es [consultado el 29 de noviembre de 2008].

Castro, Gustavo, 2004, Declaraciones de los pueblos indígenas, 13 de enero, núm. 389. CIEPAC, San Cristóbal de Las Casas.

En http://www.otrosmundoschiapas.org/analisis/DECLARADIGENAS.pdf [consultado el 3 de diciembre de 2008].

Centro de Medios Independientes, Chiapas, más testigos oculares, «Intimidaciones siguen en Ixcán», 18 diciembre 2003. En http://chiapas.mediosindependientes.org/display.php3?article_id=106767\&admin=1 [consultado el 10 de diciembre de 2008].

COPAE 2007, «El freno a los megaproyectos a través de la consulta comunitaria en Guatemala», 31 de mayo de 2007, Observatorio de las Multinacionales en América Latina, OMAL. En http://www.omal.info/www/article.php3?id_article=810 [consultado el 11 de enero de 2009].

Declaración de las comunidades y organizaciones sociales de Ixcán con motivo del día mundial de los pueblos indígenas En defensa de la tierra y los recursos naturales, 9 de agosto de 2008, Ixcán. En http://seguimientoconsulta.files.wordpress.com/2008/08/declaracion-con-motivo-aldia-mundial-de-los-pueblos-indigenas.pdf [consultado el 3 de diciembre de 2008].

Denuncia de Amnistía Internacional, 13 de noviembre de 2003. En http://asiapacific.amnesty.org/library/Index/ESLAMR340672003?open\&of=ESL2M2csalvado-003.htm [consultado el 15 de diciembre de 2008]. 
Entrevista con el alcalde Marcos Ramírez. Inforpress, 31 de marzo de 2002, boletín núm. 25. En http://www.inforpressca.com/entrev_alcalde/25-4.htm [consultado el 15 de diciembre de 2008].

Giraldo, Javier, 1994, Guatemala: la búsqueda de la verdad. En http://www.javiergiraldo.org/IMG/pdf/VyJ/05Guatemala.pdf [consultado el 25 de abril de 2006].

Prensa Libre. «Buscan desarrollo. Integran Mancomunidad de Municipios "Frontera del Norte"», 31 de agosto de 2005. En http://www.prensalibre.com/pl/2005/agosto/31/122258.html [consultado el 12 de diciembre de 2008]. Guatemala. 
Notas

${ }^{1}$ Mario Domínguez es desmovilizado de EGP, donó su relato en su entrevista, diciembre 2000. Guatemala.

${ }^{2}$ La tesis doctoral fue aprobada el 4 de septiembre de 2008 en la Universidad de Murcia, España, con el título: «Las Comunidades de Población en Resistencias CPR del Ixcán, Guatemala: el surgimiento de una nueva identidad comunitaria». Dirigida por el Dr. Gunther Dietz y la Dra. Consuelo Paterna Bleda. Este artículo es fruto de la ponencia realizada para la Mesa: Participación y cultura: expresiones de la cultura política en México y Centroamérica, del VII Congreso Centroamericano, donde presento una reflexión sobre las identidades tratadas en la investigación de la tesis doctoral, y las tendencias de su continuación en procesos de políticas actuales.

${ }^{3}$ La URNG es el partido político de izquierdas que unificó a las guerrillas en 1982. En 1984 crearon la Comandancia General, «la URNG aboga por una alianza nacional y una negociación que abran camino a una salida justa al conflicto armado. Pero ello no significa descuidar su fuerza militar» (Perales 1990: 109). «El surgimiento de la URNG, el día 7 de febrero de 1982, se enmarca en la respuesta del pueblo de Guatemala a un régimen que condujo al país al desastre más sonado de su historia, a un descrédito sin precedentes y a la desesperación social más alarmante ... La URNG ... ofrecía una perspectiva real para dar al traste con el propio sistema ... Y es expresión de los sectores populares, revolucionarios y democráticos, que luchan por la justicia, la paz y el desarrollo político y social de Guatemala» (URNG 1988: 11).

${ }^{4}$ El EGP fue fruto de la convergencia del Frente Guerrillero Edgar Ibarra, auspiciado por las FAR, de la Juventud Patriótica del Trabajo, JPT, y de estudiantes católicos del grupo Cráter. La fuerza motriz de la revolución fue el campesinado pobre indígena, y por esta razón eligieron los territorios indígenas del Altiplano occidental, donde además la presencia del ejército era muy escasa (Giraldo 1994: 14). Más tarde se unieron activistas de CUC e integrantes internacionales: médicos, maestros, etcétera.

${ }^{5}$ Acompañante se le llama a cualquier visitante a la comunidad que venga para apoyar a la población o a conocer su forma de vida y organización. Normalmente llegan de ONG, asociaciones o personas a modo individual, pero la mayoría tiene afinidades políticas progresistas. En su origen eran personas que servían para denunciar la violación de los derechos humanos a la población civil guatemalteca durante el conflicto interno, en su mayoría se encontraban tanto en las CPR como en las comunidades de desplazados, también durante los procesos de retorno. Mi contacto con los acompañantes pasó por una idealización de la que ellos mismos partían y realmente sentí cómo me la contagiaron: «por quien merece la pena hacer proyectos es por las CPR» - acompañante canario-. Era su nivel organizativo el motor de los proyectos, su experiencia organizativa era la garantía de que funcionaran.

${ }^{6}$ Esta era una función decidida por la comunidad; es una forma de distribuir las tareas y de que los acompañantes conozcan a distintas familias.

${ }^{7}$ Esta investigación se encuentra en un proceso no finalizado. En este artículo se ven tendencias importantes que deben ser consideradas, la praxis política fruto de una historia. Al ser tan reciente, se requiere de una investigación más a largo plazo. Aquí me compete la tarea de una observación explorativa de ciertas conclusiones que parten de identidades creadas por una organización comunitaria.

${ }^{8}$ Guillermo Woods fue un sacerdote de la orden de los Mariknoll, se ha convertido en un mártir para las cooperativas porque supuestamente resultó asesinado en un accidente provocado a su avioneta, se piensa que fue acusado de apoyar a la guerrilla en cuestiones logísticas, cuando lo que hacía era hacer viajes a Barillas, para traer víveres a las cooperativas o trasladar a enfermos (Falla 1992, AVANCSO 1992). Él era nombrado en todas las entrevistas donde se citaban a las cooperativas de Ixcán.

9 En Guatemala la clasificación local es el ladino criollo, o ladino mestizo. «Un ladino algo "coladito", "revuelto entre indio y ladino", para decirlo con sus propias palabras. Es decir, descendiente de aquellos ladinos que ya no existen, que desaparecieron con el mestizaje» (Adams y Bastos 2003: 295). En el Oriente de Guatemala, es utilizado para designar a un mestizo. Recoge Wilson (1999: 175) un comentario muy 
ilustrativo sobre las consecuencias en las comunidades que se componen en el norte del Quiché: "Laa'o chanchazo chirmol anaqwan [ahora estamos como huevos revueltos]».

${ }^{10}$ Los bombardeos comenzaron a finales de 1987 pero se estuvieron realizando hasta el final del conflicto. Esto fue muy duro pero la población construyó trincheras para defenderse, incluso en las construcciones comunes, como en las escuelas, para así seguir con la actividad en los momentos más duros de la resistencia.

${ }^{11}$ Las FAR nacen de la convergencia de MR-13, PGT y JPT, cuyo objetivo claro era iniciar una guerra revolucionaria. A principios de febrero de 1968 se creó en Guatemala una alianza entre MR-13 y FAR, separándose de PGT, esto posibilitaba manejar un discurso más nacionalista ajeno a las acciones más comunistas, apartándose de Cuba como centro político e ideológico (Rosada 1999: 127). Poco a poco la población organizada de la capital iba despertando a las actuaciones del gobierno, a los fraudes electorales, y comenzaba a surgir un brote guerrillero al norte del país, además de un frente en la capital. Hasta más o menos 1970 el objeto de la insurgencia era derrocar al gobierno, pero conforme radicalizaron posturas su objetivo se convirtió en «instaurar el socialismo» (Luján 1998: 330). El primer frente que crearon fue en la Sierra de las Minas, en 1968 sufrió una grave derrota por parte del ejército, la guerrilla ya es acusada de involucrar a la población, adoctrinarlos y atraerlos a su causa, además de pedirle o exigirle todo tipo de ayuda necesaria. Luján (1998: 330) lo describe en su obra y observa que el ejército desea evitar esto además de destruir sus centros de acción, ya lo define como la estrategia contrainsurgente de dejar al pez (guerrilla) sin agua (medios de autosubsistencia), estrategia que EEUU apoyó desde el principio.

${ }^{12}$ Declaraciones realizadas en 1981 por Rolando Morán, comandante en jefe de EGP (González y Campos 1983: 154-167).

${ }^{13} \mathrm{Su}$ estrategia se resume en la «doctrina de la Guerra Popular Revolucionaria», parte de la Carta de Edgar Ibarra y del Documento de Marzo de 1967, los cuales están escritos por Rolando Morán tras su participación en las FAR originarias (E-EGP Tomás 01).

${ }^{14}$ Le Bot y Stoll, en sus obras hacen referencia a este utilitarismo. Según el resultado etnográfico desde el trabajo de campo a los y las integrantes de las CPR del Ixcán, no tuve ninguna de estas afirmaciones de que sintieron un cierto abandono tras la firma de los Acuerdos de Paz. En cambio, en las entrevistas que realicé a algunos integrantes de las CPR de la Sierra, si hallé ciertos resquicios. Por tanto, de esta investigación yo analizo una simbiosis, una relación complementaria, tal vez obligada por el momento y el espacio, pero que mantiene, en la mayoría de los casos, un utilitarismo mutuo donde se introducen valores e ideologías.

${ }^{15}$ La población ixil ocupa la cintura de uno de los departamentos más pobres de Guatemala, El Quiché, habitan los terrenos de las montañas en forma de minifundios,;los ixiles han vivido en la muralla más norteña del altiplano guatemalteco por mil cuatrocientos años o más, esta área fue conquistada en 1530 por los españoles pero no hubo ningún asentamiento foráneo hasta finales del siglo XIX. Stoll (1993: 2). pone a la luz las dificultades que ha tenido este pueblo tanto con la guerrilla, el EGP, como con el ejército: «la región Ixil ... fue considerada un sólido bastión de la guerrilla y sufrió un castigo ejemplar».

${ }^{16}$ Acción Católica es un movimiento pastoral que crearon sacerdotes españoles con el fin de convertir a población maya en católicos ortodoxos. Organizaron centros en diferentes aldeas que constaba de grupos que poco a poco tuvieron una implicación importante a niveles sociales, como apoyar la construcción de escuelas y mejorar condiciones de sanidad (Stoll 1993). Piel (1997: 149) denomina a AC como «un movimiento agresivamente militante en competencia con la gerontocracia tradicionalista indígena, pero también con las otras iglesias y sectas llegadas al mismo tiempo a los parajes». Desde el inicio de la intervención de AC, se promueve la consolidación de la comunidad como algo importante para reforzar su organización, aunque desplazando sus formas e imponiendo otras nuevas que los religiosos consideraban más acertadas. Cuando comienza a organizarse el Comité de Unidad Campesina, CUC, éste «entrará al relevo de la AC y de las cooperativas y capitalizará, tal vez como en ninguna otra parte ese dinamismo comunitario» (Le Bot 1995: 163). La AC es descrita como quienes le dieron en bandeja a la guerrilla su base social, con la que habían luchado convirtiéndolos en «revolucionarios de su realidad social» (Morales 1998: 65).

${ }^{17}$ Lo que realmente diferenciaba a CUC era que le daban más importancia a las diferencias de clase que a las étnicas y culturales, al contrario de los grupos indígenas, y querían unificar demandas de los indígenas y ladinos pobres. El CUC no reivindicó intereses clasistas sino «étnico-culturales» (Torres Rivas 1996: 53), 
enriqueciendo así una perspectiva programática de la izquierda guatemalteca. Este momento era importante porque el régimen no podía controlar ideológicamente a la población (Fernández 1988). La población no necesitaba nociones de marxismo, existía un saber popular que percibía plenamente las luchas de clase latentes. Luis Gurriarán deja un testimonio sobre esto: «era una lucha espontánea, entre los que soñaban vivir con dignidad y los que sólo querían acumular riquezas» (Santos 2007: 56).

${ }^{18}$ CPI (Comité de Parcelarios de Ixcán), posteriormente se llamó CEPI (Comité Ejecutivo Primavera del Ixcán) y actualmente CCPI (Comité Coordinador de Primavera del Ixcán). Ha conservado la máxima autoridad previa a la asamblea general.

${ }^{19}$ Tienda de la cooperativa.

${ }^{20}$ Mam, chuj, q'anjob'al, q'eqchi', k'iche', poqompchi', akateko, popti' e ixil.

${ }^{21}$ Durante el conflicto bélico, algunas mujeres tomaron cargos como responsables de grupo y del comité ejecutivo, pero esto fue a menos cuando se normalizó la situación. Han sido evidente unas dificultades por cuestiones de género ya que algunos hombres trataron de mantener relaciones afectivas, provocando celos y rencores dentro de la comunidad.

${ }^{22}$ Las tradiciones mayas no fueron estudiadas en el trabajo de campo, no eran tan evidentes como otras cualidades más de índole político. Durante el trabajo de campo, la cosmovisión maya no era nombrada, las inquietudes que sobresalían eran sobre cultura política de resistencia, donde implícitamente existían parte de estos valores: solidaridad, justicia, pacifismo, etc., desconocidas para la investigadora pero que probablemente responden a una cosmovisión maya. Si el trabajo de campo lo hiciera ahora, estas características serían más visibles; que por su propio proceso histórico y tras el paso de unos años han permitido su autoconocimiento y libertad de acción.

${ }^{23}$ De todas formas, la cosmovisión maya es intrínseca a la población de CPR, se observa en su nivel de resistencia, en valores comunitarios, de solidaridad, de humanidad, que prevalecen en sus vidas, Adams (1991: 132) insiste en el carácter pacífico histórico de los indios de Guatemala cuya preocupación fundamental ha sido la de «sobrevivir en un ambiente natural fuertemente degradado por fuerzas políticas y económicas», que están muy lejos de su control. Nunca han tratado de tomar el Estado guatemalteco. Los propósitos hacia una integración panindígena en las CPR del Ixcán se observan con gran nitidez en el trabajo pastoral, ya que hay un interés por llegar a toda la población. Las lecturas del evangelio son trabajadas en tres idiomas de las etnias mayoritarias: castellano, mam y kanjobal. Mientras que en las asambleas de la comunidad no se tiene tan en cuenta, todos entienden el castellano. En CPR Ixcán, la cuestión indígena está supeditada a proyectos externos, pero esto no elimina usos y costumbres que realizan, y que estos proyectos pueden revalorizarlos entre la misma población fundamentalmente para la comunidad educativa de las mismas CPR.

${ }^{24}$ Bastos y Camus ms.; «Los indígenas de la capital». Reporte para CIRMA, en Adams, R. y Bastos, S., 2003. Las relaciones étnicas en Guatemala, 1944-2000, tomo II. CIRMA, Guatemala.

${ }^{25}$ Desde el momento de las masacres y la huida de la población de la Cooperativa Ixcán Grande, esta empezó el 14 de marzo de 1982. Marcos Ramírez quedó huérfano, y desde el primer día que la gente tuvo que huir a sus parcelas, juntó a los huérfanos de la cooperativa, ofreciéndoles las mínimas atenciones, su hermana le apoyó en hacer comida para todos. Una vez organizadas las CPR, fue tomando cargos desde los primeros comités (E-CPR M.R. 01).

${ }^{26}$ Carmelita Ross fue propuesta para pertenecer a la junta municipal; en la segunda legislatura de Marcos Ramírez participó en actividades.

${ }^{27}$ Esta sería la articulación vista durante el trabajo de campo en 1999-2001, todas las decisiones estaban supeditadas a la asamblea aunque en una red de articulación más horizontal, ya que en el comité ejecutivo se solucionan muchas cosas antes de ir a la asamblea

28 «Letra con Filo: Reencuentros y evocaciones». Por Miguel Ángel Sandoval, 3 de septiembre de 2007. http://www.albedrio.org/htm/articulos/r/rmm-027.htm. Guatemala.

${ }^{29}$ MAIZ es el Movimiento Amplio de Izquierda. Actualmente está en coalición con URNG.

${ }^{30}$ Desarrollo Integral Auténtico junto a URNG. 
${ }^{31}$ Habría que hacer un estudio para analizar esto, pero es evidente que existe una mayor participación de la población campesina y en este caso caracterizada por ser mayoritariamente indígena. Aunque fue un alcalde indígena, su discurso es propio del partido de URNG, el cual puede caracterizarse de muy plural y tiene en cuenta aspectos multiculturales, incluyendo al sector indígena, mujeres, campesinos y ladinos; priorizando sobre la población más pobre y abandonada del país. Son interesantes las investigaciones de Santiago Bastos sobre cuestiones indígenas que considera URNG (Bastos $2008 \mathrm{~ms}$, «La [ausencia de la] demanda autonómica de Guatemala)».

$32 \mathrm{http} / /$ www.inforpressca.com/entrev_alcalde/25-4.htm, 31 de marzo de 2002, boletín núm. 25.

${ }^{33}$ La Red de DDHH de Ixcán surgió en las CPR del Ixcán con el apoyo de la solidaridad.

${ }^{34}$ Denuncia por Amnistía Internacional el 13 de noviembre de 2003, principalmente por: «el ataque contra el candidato al Congreso Rolando Morales y por la intimidación contra el alcalde electo Marcos Ramírez» junto a miembros de la junta municipal y quienes están relacionados. Y para que se adhirieran todos los partidos políticos al pacto de no violencia.

${ }^{35}$ Como investigadora de la identidad de CPR del Ixcán, me remito a la relación existente en la identidad con los apoyos externos, en este caso que continúan, como es la Pastoral Social, donde muchos integrantes son seguidores de la teología de la liberación, SIEMBRA; una ONG donde se integraron desmovilizados, en su mayoría del EGP entre otros, y MINUGUA, donde se percibe este asesoramiento internacional. Pese a muchas discusiones de algunas personas de las CPR, de la Sierra y de Ixcán, que sintieron el abandono por parte de la guerrilla, junto a autores como Le Bot (1995) y Stoll (1993) que cercioran la instrumentalización de los indígenas durante el conflicto bélico, tal vez pueda existir un tipo de autoculpa... y por eso siguen apoyando a la población más pobre del país que aún sufre las consecuencias de la guerra y los procesos políticos actuales.

${ }^{36} \mathrm{http} / / /$ chiapas.mediosindependientes.org/display.php3?article_id=106767\&admin=1, 18 diciembre 2003.

${ }^{37}$ Declaraciones de los pueblos indígenas, Gustavo Castro Soto, 13 de enero de 2004, núm.389, CIEPAC, San Cristóbal de Las Casas, Chiapas.

${ }^{38}$ Álvaro Caballeros, AVANCSO/CENINF, Observador de la Consulta en la Comunidad de Xalalá, Ixcán, Guatemala. Con información de Comisión Organizadora y la Asociación Coordinadora Comunitaria de Servicios para la Salud, ACCSS. http://alainet.org/active/17083\&lang=es

39 Boletín Semanal de la Plataforma Agraria, año 6, núm. 13, semana de 17 a 23 de abril de 2007. http://www.albedrio.org/htm/articulos/c/

40 «Integran Mancomunidad de Municipios "Frontera del Norte"». Prensa Libre, 31 de agosto de 2005. http://www.prensalibre.com/pl/2005/agosto/31/122258.html. Guatemala.

Fecha de recepción: 7 de mayo de 2009.

Fecha de aceptación: 1 de julio de 2009. 